\title{
A Causality Analysis of Coal Consumption and Economic Growth for China and India
}

\author{
Jinke $\mathrm{Li}^{1,2}$, Zhongxue $\mathrm{Li}^{2}$ \\ ${ }^{1}$ Management Science and Technology School, Shandong Institute of Business and Technology, Yantai, China. \\ ${ }^{2}$ Civil and Environmental Engineering School, University of Science and Technology Beijing, Beijing, China. \\ Email: jinkeli@yahoo.com.cn
}

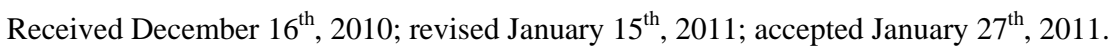

\begin{abstract}
China and India are the two countries with the strongest economic growth in the world. Meanwhile they consume much of the global coal to fuel their economic development. With coal burning as a major factor contributing to global greenhouse gas emissions, China and India are confronted with a dilemma of economic growth and environment protection. Will coal consumption reduction cause economic shocks? Is there a causal relationship between coal consumption and economic growth in China and India? In this paper Granger causality tests were used to examine the relationship between coal consumption and GDP in China and India, using data for the period from 1965 to 2006. It was found that a unidirectional causality from GDP to coal consumption existed in China while a unidirectional causality from coal consumption to GDP did in India. Therefore, developing cleaner and more efficient technologies is essential to reduce their $\mathrm{CO}_{2}$ emissions to reach sustainable development.
\end{abstract}

Keywords: Causality Relationshi, Economic Growth, Coal Consumption

\section{Introduction}

China and India are the emerging economic giants in the world; the economic growth in China was the world's fourth largest and that in India was the 13th in 2006. During the period of 1965-2006, China's average annual growth in real GDP was $6.5 \%$ and India's was $4.8 \%$. In recent years, the economies of both countries have been growing more rapidly. China's economic growth rate went from $10.4 \%$ in 2005 to $11.1 \%$ in 2006 , while India's increased from 9\% in 2005 to $9.7 \%$ in 2006 [1]. China and India's economies are still growing strongly even global financial crisis already causing downturn in developed economies. In the WEO (World Economic Outlook) reference scenario, primary energy use needs to expand at an average annual rate of $3.2 \%$ in China and $3.6 \%$ in India-much faster than that in the rest of the world. The two countries together account for $20 \%$ of the world's primary energy use by 2006 and this share will increase to $29 \%$ by 2030 [1].

Both China and India have been heavily depending on coal to energize their economies. In 2009 coal consumption was up in China (including Hong Kong) by $15.2 \%$ and India by $9.0 \%$ [2]. By 2030, coal will make up $59 \%$ of the two countries' combined energy needs:
63\% in China and 48\% in India [3]; China remains the world's largest consumer of coal, while India becomes the second-largest. The increased use of coal will inevitably result in rising global $\mathrm{CO}_{2}$ emissions. BP (British Petroleum) statistics suggested that coal discharges 1.08 tons carbon per ton oil equivalent, while natural gas and oil discharge 0.64 and 0.84 tons respectively [4]. Largely as a result of their heavy reliance on coal, the energy related emissions of carbon dioxide are soaring in China and India. China's $\mathrm{CO}_{2}$ emissions already have surpassed those of the U.S. and become the world's largest emitter and by 2015 India will be the third largest emitter.

In developing countries such as China and India, coal is indeed a double edged sword - the new economy's black gold and the fragile environment's dark cloud. Despite impressive rates of economic growth and industrialization in recent years, both China and India remain poor by OECD standards, and they both need to sustain a phenomenal rate of economic growth. However, until environmental protection measures become available, sustainable development of their economies will be limited.

Is there a causal relationship between coal consumption and economic growth, or is the extent of causality the same in China as in India? This current paper at- 
tempts to answer these questions using the Granger causality analysis.

\section{Review of the Literature}

With the energy crisis in the 1970s and 1980s and the increasing energy prices in recent years, the relationship between energy consumption and economic growth has received increasing attentions.

There are two techniques commonly used to analyze the relationship between energy consumption and economy growth. One approach is to establish an economy growth model that includes energy factors and technological change to explore the influences of energy on economy growth. Smulders [5] constructed an economic growth model in which energy and endogenous technological advancement factors were used to explain the widespread increase in the total energy consumption and improvement in the efficiency of energy use in the OECD countries; Azomahou [6] built a general equilibrium model with energy-saving technological progress as the factor leading to the fall of energy intensity found in OECD countries over the past 20 years.

However, more studies were focused on the causality relationship between energy consumption and GDP. Kraft, J. and Kraft, A. [7] found that there is a unidirectional causality running from energy consumption to GNP for the United States during the period of 1947-1974. Since then, the number of literatures on Granger causality has grown considerably not only in developed countries but also in developing countries such as China and India. Soytas and Sari [8] studied the causality relationship in G7 countries and emerging markets; Lee [9] analyzed the cases of 11 major industrialized countries; Glasure and Lee [10] used the example of South Korea and Singapore to study the causality relationship between energy consumption and GDP; Oh and Lee [11] analyzed the case of Korea from 1970 to 1999; Al-Iriani [12] gave an example in GCC countries using panel causality; Yoo [13] studied the causality relationship between electricity consumption and economic growth in the ASEAN countries; Ferguson et al. [14] studied the issue of electricity consumption and economic growth in over 100 countries and found that as a whole there is a strong correlation between electricity consumption and economic growth; Alice Shiu[15] and Sajal Ghosh [16] gave the examples of electricity consumption and economic growth in China and India respectively; Narayan [17] provided Electricity consumption and real GDP causality for 30 OECD countries; Yang [18] found causality relationship from economic growth to coal consumption in Taiwan; Yoo [19] showed that there existed a bi-directional causality relationship between coal consumption and economic growth in
South Korea; Jinke [20] uses Granger causality tests to examine the differences of causal relationships between coal consumption and GDP in major OECD and non-OECD countries, using data for the period of 1980-2005; Apergis [21] examines the relationship between coal consumption and economic growth for 25 OECD countries within a multivariate panel framework over period 1980-2005; Wolde [22] revisits the causal relationship between coal consumption and real GDP for six major coal consuming countries for the period 1965-2005; Apergis [23] also examines the relationship between coal consumption and economic growth for 15 emerging market economies within a multivariate panel framework over the period 1980-2006.

It is known that different causality relationships between economic growth and coal consumption suggest different energy conservation and economic growth policies. If there exists causality running from coal consumption to GDP, it implies that a shortage of coal may negatively affect GDP; otherwise if a unidirectional causality runs from economic growth to coal consumption, it could imply that the policies for reducing coal consumption may be implemented with little effect on economic growth. The purpose of this study is to determine such relationship between coal consumption and economic growth for China and India to give suggestions for policy decision making.

\section{Coal Consumption in China and India}

\subsection{Coal Dependency}

China's remaining coal resources are next to USA's and Russia's, totaling 1003 billion tons [24]. India has the world's fourth largest hard coal resources [25] with the total estimated at 255 billion tons. Abundant domestic coal resources make both countries heavily dependent on coal.

The share of coal in primary energy use is much higher in China-at 63\% in 2005, compared with 39\% in India. The importance of coal in the overall fuel mix has been growing due to the booming demand for electricity. Oil's share reached $19 \%$ and $24 \%$ respectively in China and India in 2005. The use of nuclear power is less than $1 \%$ of primary energy and that of renewable energy (with the exception of traditional biomass and hydropower), is very limited. The energy mixes for both countries are shown in Figure 1.

\subsection{Coal Consumption and Economic Growth}

With the rapid growth of economy, the coal consumption grew concurrently in both China and India. Figure 2 and Figure 3 show the 1965-2006 national coal consumption and GDP trends and it appears that there is a close rela- 


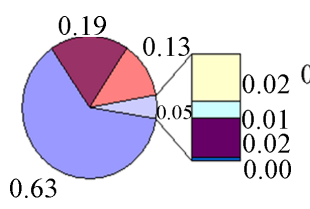

a) China

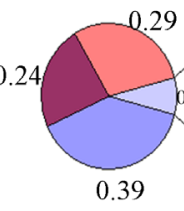

.39

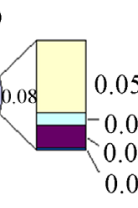

b) India
Figure 1. Energy mix of China and India in 2005.

tionship between coal consumption and economic growth. But it needs to be testified. In addition, it needs to be investigated weather coal consumption causes economic growth or vice versa. The causal relationship between coal consumption and economic growth needs to be further studied.

To reflect the economy's reliance on coal consumption, the coal consumption intensity (CCI) is defined and it is the ratio of the coal consumption to the real national economic amount in GDP. As shown in Figure 4, the CCI of China fluctuated and gradually decreased after 1980, indicating that the economy's reliance on coal has been gradually dropped. However, it is still much higher as compared with that of India which is stable and low.

\section{Causality Analysis Methodology and Results}

The annual time series for China and India used in this study are the annual time series of real GDP and they are obtained from The Conference Board and Groningen Growth and Development Centre [26]. Real GDP is expressed in millions of 1990 US\$ (converted at GearyKhamis PPPs). The Coal consumption data is from BP [4] and the unit of Coal consumption is MTOE.

From Figure 2 and Figure 3, it can be seen that a long term relationship may exist between coal consumption and GDP growth. The unit root and co-integration tests were used to verify such a relationship. The empirical period was 1965-2006 with all variables measured in natural logarithms.

To conduct the Granger-causality test, a series of variables are required to be stationary. It has been shown that spurious causality results can occur if non-stationary data is used in causality tests. This paper used the Fisher-type ADF (Augmented Dickey-Fuller) and PP (PhillipsPerron) panel unit root tests proposed by Maddala and $\mathrm{Wu}$ [27] to confirm the stationarity of the series of variable.

\subsection{Unit Root Tests}

Recent literatures suggest that panel-based unit root tests are more powerful than unit root tests based on individual time series and therefore the Fisher-type ADF and PP tests are used in this paper. A Schwarz criterion is adopted to select the optimal number of lag length and

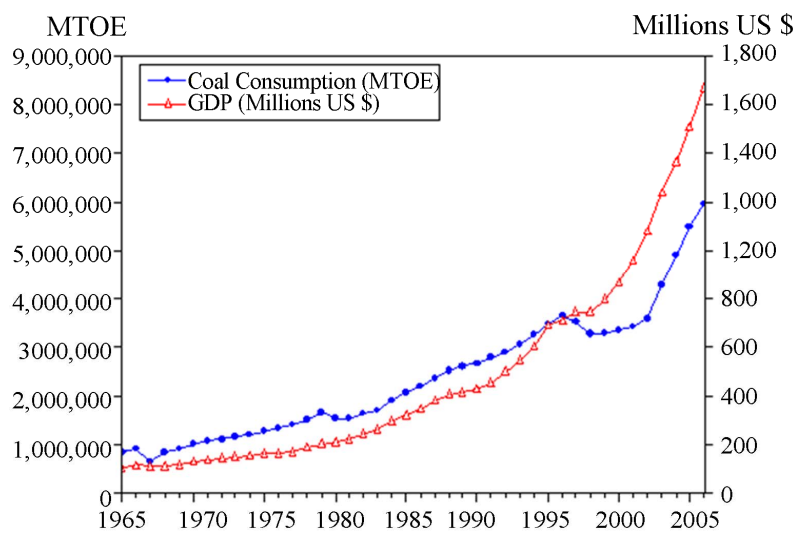

Figure 2. Coal consumption and GDP in China 1965-2006.

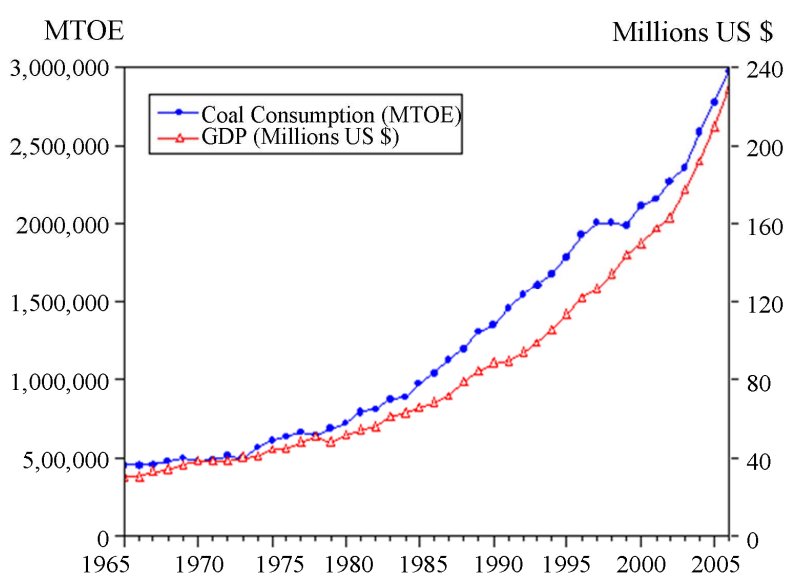

Figure 3. Coal consumption and GDP in India 1965-2006.

the kernel type of Bartlett is selected for kernel based methods. The results of the panel unit root tests are presented in Table $\mathbf{1 .}$

In Table 1, LNGDP denotes natural logarithms of

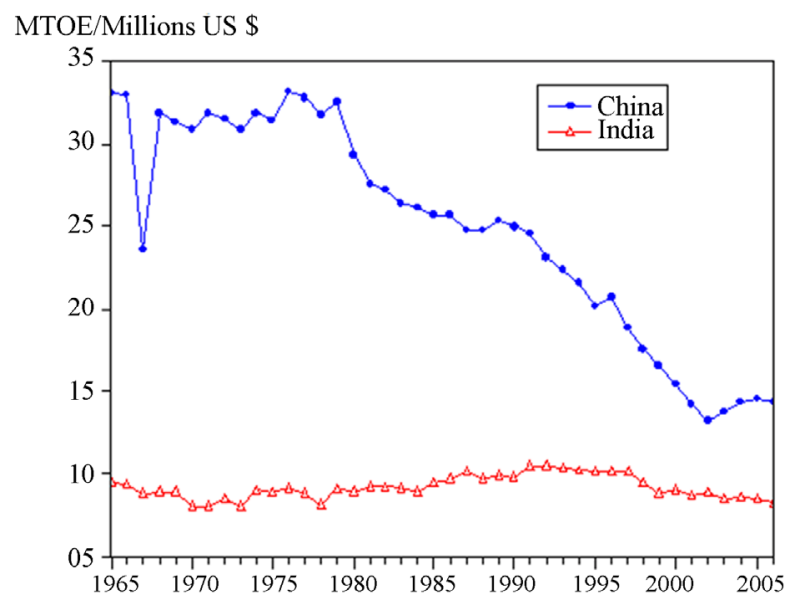

Figure 4. Coal consumption Intensity of China and India 1965-2006. 
Table 1. Panel unit root test results of ADF-Fisher and PPFisher.

\begin{tabular}{cccccc}
\hline & \multicolumn{2}{c}{ ADF-Fisher } & & \multicolumn{2}{c}{ PP-Fisher } \\
\cline { 2 - 3 } \cline { 6 - 7 } & No Trend & Trend & & No Trend & Trend \\
\hline \multirow{2}{*}{ LNGDP_CN } & $4.4197 \mathrm{e}-05$ & 2.0955 & & $1.7 \mathrm{E}-6$ & 0.2890 \\
& $(1.0000)$ & $(0.3507)$ & & $(1.0000)$ & $(0.8654)$ \\
LNGDP_IN & $5.2 \mathrm{e}-05$ & 0.0609 & & $7.7 \mathrm{e}-10$ & 0.0226 \\
& $(1.0000)$ & $(0.9700)$ & & $(1.0000)$ & $(0.9887)$ \\
LNCOAL_CN & 0.0354 & 2.8196 & & 0.0510 & 4.3951 \\
& $(0.9825)$ & $(0.2442)$ & & $(0.9748)$ & $(0.1111)$ \\
LNCOAL_IN & 0.0041 & 3.2571 & & 0.0041 & 3.2587 \\
& $(0.9980)$ & $(0.1962)$ & & $(0.9980)$ & $(0.1961)$ \\
D(LNGDP_CN) & $13.0328^{*}$ & $14.1965^{*}$ & & $13.0328^{*}$ & $14.3574^{*}$ \\
& $(0.0015)$ & $(0.0008)$ & & $(0.0015)$ & $(0.0008)$ \\
D(LNGDP_IN) & $26.5242^{*}$ & $29.9559^{*}$ & & $26.4918^{*}$ & $38.5809^{*}$ \\
& $(0.0000)$ & $(0.0000)$ & & $(0.0000)$ & $(0.0000)$ \\
D(LNCOAL_CN) & $32.0230^{*}$ & $29.8642^{*}$ & & $31.8287^{*}$ & $29.4554^{*}$ \\
& $(0.0000)$ & $(0.0000)$ & & $(0.0000)$ & $(0.0000)$ \\
D(LNCOAL_IN) & $24.1433^{*}$ & $21.2326^{*}$ & & $24.1449^{*}$ & $21.2326^{*}$ \\
& $(0.0000)$ & $(0.0000)$ & & $(0.0000)$ & $(0.0000)$ \\
\hline
\end{tabular}

Note: *denotes statistical significance at the $1 \%$ level.

GDP of each country and LNCOAL denotes natural logarithms of coal consumption. D denotes the 1st difference of LNGDP. The results of the ADF-Fisher and PP-Fisher unit root tests for the levels of LNGDP and LNCOAL are not able to reject the unit root null hypothesis at the $5 \%$ level. However, when the unit root tests for the first differences of each series are conducted, the null hypothesis can be rejected at the $5 \%$ level. It shows that LNGDP and LNCOAL has one unit root thus to be I (1) variables in China and India, then the Grangercausality models are estimated with first-differenced data.

\subsection{Co-Integration Tests}

According to Engle and Granger [28], if both time series are non-stationary, the linear combination of the two time series would be stationary and thus they are co-integrated. Tests of co-integration include the simple two-step test by Engle and Granger (EG) and Johansen's vector auto-regression [29] for more than one co-integrating relationship. The two-step test EG is used in this paper.

First-step: Estimating co-integration equation in the form of $L N G D P_{t}=\alpha+\beta L n C O A L_{t}+\varepsilon_{t}$ to obtain $\hat{\alpha}$, $\hat{\beta}$ and $\hat{\varepsilon}=L N G D P_{t}-\hat{\alpha}-\hat{\beta} L N C O A L_{t}$

Second-step: if $A D F$ test indicates $\hat{\varepsilon} \sim I(0)$, then $\varepsilon_{t}$ is stationary, and LNGDP and LNCOAL are co-integrated.

Having OLS estimated the above model of coal consumption and GDP series, ADF-Fisher and PP-Fisher unit root tests for $\varepsilon_{t}$ are conducted.
Table 2 indicates the test results on the levels of GDP and coal consumption at the corresponding significant level. The results strongly support the conclusion that a long-run causality relationship between the variables does exist for China and India.

\subsection{Granger Tests and Causality Results}

Co-integration implies the existence of Granger causality, but it does not point out the direction of the causality relationship. Therefore, the vector error correction model (ECM) is used to detect the direction of the causality. Engle and Granger have argued if there was co-integration between the time series, then the vector error correction model can be written as:

$$
\begin{aligned}
\Delta L N G D P_{t}= & \alpha_{10}+\sum_{i=1}^{k} \alpha_{1 i} \Delta L N G D P_{t-i} \\
& +\sum_{i=1}^{k} \beta_{1 i} \Delta L N C O A L_{t-i}+\gamma_{1} e c m_{1 t-1}+\varepsilon_{1 t} \\
\Delta L N C O A L_{t}= & \alpha_{20}+\sum_{j=1}^{m} \alpha_{2 j} \Delta L N C O A L_{t-j} \quad \text { where } \\
& +\sum_{j=1}^{m} \beta_{2 j} \operatorname{LNGDP}_{t-j}+\gamma_{2} e c m_{2 t-1}+\varepsilon_{2 t}
\end{aligned}
$$

$\Delta$ is the difference operator, $\mathrm{k}$ and $\mathrm{m}$ are the numbers of lags, $\beta_{1, \mathrm{i}}, \beta_{2, \mathrm{j}}$ are parameters to be estimated, ecm is the error terms derived from the long-run co-integration relationship of $L N G D P_{t}=\alpha+\beta L N C O A L_{t}+\varepsilon_{t}$, and $\varepsilon_{1, i}, \varepsilon_{2, j}$ are the serially uncorrelated error terms.

The results of the Granger causality tests of the model are shown in Table 3. The table also shows the tests used to choose the lag lengths. The results in Table 3 provide a convincing evidence of a unidirectional causality running from LNGDP to LNCOAL for China at the 5\% level of significance. There exists a unidirectional causality running from LNCOAL to LNGDP for India at the same significant levels.

\subsection{Comparison with other Related Results}

To compare the causality between coal consumption and

\begin{tabular}{|c|c|c|}
\hline & ADF - Fisher & PP - Fisher \\
\hline Summary & $10.5478^{* * a}(0.0321)$ & $13.6953^{* \mathrm{~b}}(0.0083)$ \\
\hline $\mathrm{ECN}$ & $-2.5456^{* *}(0.0122)$ & $-2.5065^{* *}(0.0135)$ \\
\hline EIN & $-2.4342^{* *}(0.0168)$ & $-2.0985^{* *}(0.0359)$ \\
\hline
\end{tabular}
economy growth with other related results, the causality between energy use and economy growth or electricity consumption and economy growth have been reviewed

Table 2 .Panel unit root test results of $\hat{\varepsilon}$. 
Table 3 Results of causality tests based on ECM.

\begin{tabular}{cclll}
\hline & Null hypotheses & p-values & Lags & Direction of causality \\
\hline \multirow{2}{*}{ CN } & $L N C O A L \neq>^{b} L N G D P$ & 0.2805 & \multirow{2}{*}{$2^{\text {a }}$} & $L N C O A L \neq>L N G D P$ \\
& $L N G D P \neq>L N C O A L$ & 0.0004 & & $L N G D P \Rightarrow$ c $L N C O A L$ \\
\multirow{2}{*}{ IN } & $L N C O A L \neq>L N G D P$ & 0.0169 & & $L N C O A L \Rightarrow L N G D P$ \\
& $L N G D P \neq>L N C O A L$ & 0.7875 & & $L N G D P \neq>L N C O A L$ \\
\hline
\end{tabular}

Notes: ${ }^{\mathrm{a}}$ The lag lengths are chosen by using AIC criterion; the statistics are p-values calculated under the null hypothesis of no causation. ${ }^{\mathrm{b}} \not>>$ denotes statistical insignificance and, hence fails to reject the null hypothesis of non-causality. ${ }^{\mathrm{c}} \Rightarrow$ denotes the rejection of the null hypothesis of non-causality.

Table 4. Comparison with energy and electricity.

\begin{tabular}{ccccc}
\hline Country & Comparison & Sources & Study period & Causal relationship \\
\hline \multirow{4}{*}{ China } & Energy and GDP & Han Zhiyong etc. [30] & $1978-2000$ & $E n^{a} \Leftrightarrow G^{b}$ \\
& Electricity and GDP & Alice Shiu [15] & $1971-2000$ & $E \Rightarrow^{d} G$ \\
& Coal and GDP & This case & $1965-2006$ & $G C^{c}$ \\
& & & & $E \Leftrightarrow^{e} G$ \\
India & Energy and GDP & Paul and Bhattacharya [31] & $1950-1996$ & $G \Rightarrow E$ \\
& Electricity and GDP & Sajal Ghosh [16] & $1950-51$ to 1996-97 & $C \Rightarrow G$ \\
& Coal and GDP & This case & $1965-2006$ & \\
\hline
\end{tabular}

Notes: ${ }^{\mathrm{a}}$ En denotes energy consumption, ${ }^{\mathrm{b}} \mathrm{G}$ denotes GDP; ${ }^{\mathrm{c}} \mathrm{C}$ denotes coal consumption; E denotes electricity consumption. ${ }^{\mathrm{d}} \Rightarrow$ denotes unidirectional causality, ${ }^{\mathrm{e}} \Leftrightarrow$ denotes bi-directional causality.

and listed in Table 4. It can be seen that there exists bi-directional causality relationship running from energy consumption and GDP in China and India; it sounds fair and reasonable because both developing countries need more energy to fuel the economy, meanwhile rapid economy growth stimulates the energy consumption. Regarding electricity there exists unidirectional causality relationship running from electricity consumption to GDP in China, and unidirectional causality relationship running from GDP to electricity consumption in India, the reasons are also expounded in Alice Shiu's [15] and Sajal Ghosh's [16] study respectively.

Higher economic growth in China stimulates their demand for energy including coal, soaring coal consumption is a consequence of the remarkable growth in the country's economy-especially in heavy industry; on the other hand, China's economic expansion has been largely based on capital formation; increased labor input has made only a marginal contribution to GDP growth.

China is often characterized as the world's workshop with growth driven largely by production and exports of manufactured goods. By comparison of exports and investment together accounted for about $80 \%$ of GDP in 2006, coal consumption contribution to economy growth is not significant.

In India, the share of coal in total energy use in industry was at around 41\% in 1990 and around 30\% in 2005. India's industry has experienced faster gains, it contributed $27 \%$ of the GDP in 2005, and it was the main reason for higher output growth since 2003. With the economy expanding the economy may stimulate more electricity rather than coal consumption, because there existed uni- directional causality relationship running from GDP to electricity consumption in Sajal Ghosh' study [16].

\section{Conclusion and Policy Implications}

The evidence and direction of causality between coalconsumption and economic growth in China and India have been given and the following conclusions can be drawn.

1) The unidirectional causality from GDP to coal consumption in China indicates that the continuous economic growth has resulted in a continuous rise in coal consumption which is fundamentally driven by GDP and therefore taking measures to conserve coal without compromising economic growth may be feasible. For example, China may overcome heavy dependence on coal in the long run by relying more on hydropower and natural gas. The unidirectional causality from coal consumption to GDP in India indicates that a change in coal consumption directly affects economic growth and coal constitutes a critical factor in sustaining the nation's economic growth and well being. The efforts to implement coal saving and emission reduction policies would slow down the economic growth in India, if India is to continue following exactly the same economic growth model as in the past 40 years.

2) Various causal patterns for coal consumption, electricity consumption and energy consumption and the economic growth in China and India are observed and they may be resulted from different energy consumption structures and economic policies in the two countries.

3) Economic growth is one of the most important factors influencing coal consumption and the outlook for 
coal use depends on relative fuel prices and government policies on fuel diversification, climate change and air pollution. Policy coordination, technology collaboration and financial aids by governments and industry are required to reduce the consumption of coal and the $\mathrm{CO}_{2}$ emissions from coal use.

4) The panel-based ADF-Fisher and PP-Fisher unit root tests, the two-step EG test, and the VECM have been used to examine stationarity, co-integration, and causality related with coal consumption and GDP for China and India. Further analysis integrating economic factors such as price, employment, and export into the models will augment the results.

Units and technical abbreviations

GDP: gross domestic product

BNC: billion national currencies

MTOE: million tons oil equivalent

\section{Acknowledgements}

This work was financially supported by a project (10CGL052) from the National Society Science Foundation of China and from the Shandong Provincial Department of Education.

\section{REFERENCES}

[1] International Energy Agency (IEA). Coal Information 2007 with 2006 data. IEA Publications, Paris.

[2] International Energy Agency (IEA). WORLD ENERGY OUTLOOK 2010. IEA Publications, Paris.

[3] International Energy Agency (IEA). WORLD ENERGY OUTLOOK 2007 China and India Insight. IEA Publications, Paris.

[4] BP. The BP Statistical Review of World Energy, 2007. http://www.bp.com/statistical.review

[5] S. Sjak and M. D. Nooij, "The Impact of Energy Conservation on Technology and Economic Growth," Resource and Energy Economics, Vol. 25, No. 1, 2003, pp. 59-79. doi:10.1016/S0928-7655(02)00017-9

[6] T. Azomahou, R. Boucekkine and N. V. Phu, "Energy Consumption, Technological Progress and Economic Policy,” Université catholique de Louvain, IRES Discussion Paper, No. 2003025.

[7] J. Kraft and A. Kraft, "On the Relationship between Energy and GNP,” Journal of Energy Development, Vol. 3, No. 2, 1978, pp. 401-403.

[8] U. Soytas and R. Sari, "Energy Consumption and GDP: Causality Relationship in G-7 Countries and Emerging Markets," Energy Economics, Vol. 25, No. 1, 2003, pp. 33-37. doi:10.1016/S0140-9883(02)00009-9

[9] C. C. Lee, “The Causality Relationship between Energy Consumption and GDP in G-11 Countries Revisited," Energy Policy, Vol. 34, No. 9, 2006, pp. 1086-1093. doi:10.1016/j.enpol.2005.04.023
[10] C. C. Lee, "Energy Consumption and GDP in Developing Countries: A Cointegrated Panel Analysis,” Energy Economics, Vol. 27, No. 3, 2005, pp. 415-427. doi:10.1016/j.eneco.2005.03.003

[11] W. Oh and K. Lee, "Causal Relationship between Energy Consumption and GDP Revisited: the Case of Korea 1970-1999,” Energy Economics, Vol. 26, No. 1, 2004, pp. 51-59. doi:10.1016/S0140-9883(03)00030-6

[12] M. A. Al-Iriani, "Energy-GDP Relationship Revisited: An Example from GCC Countries Using Panel Causality,” Energy Policy, Vol. 34, No. 17, 2006, pp. 3342-3350. doi:10.1016/j.enpol.2005.07.005

[13] S. Yoo, "The Causal Relationship between Electricity Consumption and Economic Growth in the ASEAN Countries," Energy Policy, Vol. 34, No. 18, 2006, pp. 3573-3582. doi:10.1016/j.enpol.2005.07.011

[14] R. Ferguson and H. R. Wilkinson, "Electricity Use and Economic Development,” Energy Policy, Vol. 28, No. 13, 2000, pp. 923-934. doi:10.1016/S0301-4215(00)00081-1

[15] A. Shiu and P. L. Lam, "Electricity Consumption and Economic Growth in China,” Energy Policy, Vol. 32, No. 1, 2004, pp. 47-54. doi:10.1016/S0301-4215(02)00250-1

[16] S. Ghosh, "Electricity Consumption and Economic Growth in India,” Energy Policy, Vol. 30, No. 2, 2002, pp. 125-129. doi:10.1016/S0301-4215(01)00078-7

[17] P. K. Narayan, I. Nielsen, et al., "Panel Data, Cointegration, Causality and Wagner's Law: Empirical Evidence from Chinese Provinces," China Economic Review, Vol. 19, No. 2, 2008, pp. 297-307. doi:10.1016/j.chieco.2006.11.004

[18] H. Y.Yang, "Coal Consumption and Economic Growth in Taiwan,” Energy Sources, Vol. 22, No. 2, 2000, pp. 109-115. doi:10.1080/00908310050014081

[19] S. Yoo, "Causal Relationship between Coal Consumption and Economic Growth in Korea," Applied Energy, Vol. 83, No. 11, 2006, pp. 1181-1189. doi:10.1016/j.apenergy.2006.01.010

[20] L. Jinke, S. Hualing, et al., "Causality Relationship between Coal Consumption and GDP: Difference of Major OECD and non-OECD Countries,” Applied Energy, Vol. 85, No. 6, 2008, pp. 421-429. doi:10.1016/j.apenergy.2007.10.007

[21] N. Apergis and J. E. Payne, "The Causal Dynamics between Coal Consumption and Growth: Evidence from Emerging Market Economies,” Applied Energy, Vol. 87, No. 62010, 2010, pp. 1972-1977. doi:10.1016/j.apenergy.2009.11.035

[22] R. Y. Wolde, "Coal Consumption and Economic Growth Revisited,” Applied Energy, Vol. 87, No. 1, 2010, pp. 160-167. doi:10.1016/j.apenergy.2009.05.001

[23] N. Apergis and J. E. Payne, "Coal Consumption and Economic Growth: Evidence from a Panel of OECD Countries,” Energy Policy, Vol. 38, No. 3, 2010, pp. 1353-1359. doi:10.1016/j.enpol.2009.11.016

[24] G. B. General, “China’s Mineral Resources, Volume I-Energy Mineral Resources,” Geological Publishing Com- 
pany, Beijing, 1999.

[25] BGR. "Reserves, Resources and Availability of Energy Resources-Annual Report 2005,” Federal Institute for Geosciences and Natural Resources, Hanover, 2007. http: // www.bgr.bund.de

[26] Conference Board and Groningen Growth and Development Centre, Total Economy Database, 2008. http://www.c onference-board.org/economics/

[27] G. S. Maddala and S. Wu, "A Comparative Study of Unit Root Tests with Panel Data and A New Simple Test," Oxford Bulletin of Economics and Statistics, Vol. 61, No. 0, 1999, pp. 631-652. doi:10.1111/1468-0084.61.s1.13

[28] R. Engle and C. Granger, "Cointegration and Error Correction: Representation, Estimation, and Testing," In Econometrica, Vol. 55, No. 2, 1987, pp. 257-276.

\section{doi:10.2307/1913236}

[29] S. Johansen, "Statistical Analysis of Cointegration Vectors," In Journal of Economic Dynamics and Control, Vol. 12, No. 2, 1988, pp. 231-254. doi:10.1016/0165-1889(88)90041-3

[30] Z. Y. Han, Y. M. Wei and J. J. "On the Cointegration and Causality between Chinese GDP and Energy Consumption,” Systems Engineering (in Chinese) Vol. 12, 2004, pp.17-21.

[31] S. Paul, R. N. Bhattacharya, "Causality between Energy Consumption and Economic Growth in India: A Note on Conflicting Results,” Energy Economics, Vol. 26, No. 6, 2004, pp. 977-998. doi:10.1016/j.eneco.2004.07.002 